\title{
O feminino e o masculino no conto de fadas $A$ moça tecelã, de Marina Colasanti: reflexões sobre o letramento crítico.
}

\section{Julia Rodrigues Chagas Cabral}

Pontifícia Universidade Católica do Rio de Janeiro - PUC-Rio/CNPq ${ }^{1}$

\begin{abstract}
Resumo
Neste artigo reflito sobre o letramento crítico (CERVETTI, PARDALES \& DAMICO 2001; MCLAUGHLIN, DEVOOGD, 2004), focalizando o conto "A moça tecelã", de Marina Colasanti, à luz da linguística sistêmicofuncional (HALLIDAY \& MATTHIESSEN, 2014). Para isso, foram traçados os seguintes objetivos: i) identificar e classificar processos, participantes e circunstâncias associados às personagens feminina e masculina; ii) analisar e interpretar as escolhas lexicogramaticais da autora e iii) discutir de que modo as representações das personagens do conto podem ser usadas para problematizar as relações sociais entre homens e mulheres em contextos pedagógicos. Este é um estudo de natureza qualitativa interpretativista (DENZIN \& LINCOLN, 2006) que tenciona aprofundar o diálogo sobre a leitura em sala de aula em uma perspectiva crítica.

Palavras-chave: letramento crítico, linguística sistêmico-funcional, Marina Colasanti.
\end{abstract}

\begin{abstract}
In this paper, I reflect on critical literacy (CERVETTI, PARDALES \& DAMICO 2001; MCLAUGHLIN, DEVOOGD, 2004), focusing on the story "A moça tecelã," by Marina Colasanti, from the perspective of systemic-functional linguistics (HALLIDAY \& HASAN, 1989; HALLIDAY, 1994; HALLIDAY \& MATTHIESSEN,2014). The analysis was done in line with the following objectives: i) identify and classify processes, participants, and circumstances associated with the female and male characters; ii) analyze and interpret the lexicogrammatical choices of the author, and iii) discuss how the representations of the characters in the story can be used for rethinking the social relations between men and women in pedagogical contexts. This is a study of a qualitative interpretative nature (DENZIN \& LINCOLN, 2006) that seeks to further the dialogue about reading in the classroom from a critical perspective.

Keywords: critical literacy, systemic-functional linguistics, Marina Colasanti.
\end{abstract}

\footnotetext{
${ }^{1} \mathrm{O}$ presente trabalho foi realizado com apoio do CNPq, Conselho Nacional de Desenvolvimento Científico e Tecnológico - Brasil
} 


\section{INTRODUÇÃO}

Desenvolver as habilidades e as práticas de leitura de nossos alunos é uma das funções principais do ensino de língua materna ou estrangeira e, por isso, o trabalho com texto em sala de aula deve ser matéria constante de nossas reflexões. Neste artigo, proponho e discuto o letramento em uma perspectiva crítica, que tem como objetivo promover entre os alunos uma postura reflexiva diante dos mais variados textos que circulam em nossa sociedade (CERVETTI, PARDALES \& DAMICO 2001; MCLAUGHLIN, DEVOOGD, 2004). A ideia que norteia este trabalho é a compreensão de que, além do conteúdo gramatical, o ensino de língua portuguesa deve abarcar também a formação de um pensamento crítico e reflexivo.

Para tanto, focalizo o conto de fadas “A moça tecelã”, de Marina Colasanti, à luz da linguística sistêmico-funcional (HALLIDAY \& MATTHIESSEN, 2014) e procuro destacar questões que podem ser exploradas no contexto pedagógico a partir de uma compreensão crítica.

A autora retoma os contos de fadas em sua produção literária, porém se distancia em diversos aspectos do paradigma tradicional dessas histórias. Sua obra se enquadra em uma concepção contemporânea do gênero, o conto de fadas moderno ${ }^{2}$, e dialoga com temas atuais relativos ao universo feminino. Assim, busquei gerar entendimentos sobre a representação das personagens feminina e masculina no texto selecionado a partir da análise dos elementos do Sistema de Transitividade, ligado à Metafunção Ideacional da linguagem.

São objetivos específicos desse trabalho: i) identificar e classificar processos, participantes e circunstâncias associados a tais personagens; ii) analisar e interpretar as escolhas lexicogramaticais da autora, iii) discutir algumas questões que podem ser problematizadas a partir do conto e a relevância de abordá-las no contexto pedagógico.

Promover a leitura em sala de aula com um viés crítico possibilita o trabalho com os textos sem perder de vista sua relação com o meio social em que são produzidos e interpretados e, ainda, os valores, projetos políticos e as ideologias que representam. Nessa perspectiva, os alunos são estimulados a observarem o que, como, por quem e pra quem um texto foi escrito e assim problematizarem o que leem. Discutir tal abordagem,

\footnotetext{
${ }^{2}$ O conceito será melhor explicitado na subseção de contextualização do conto.
} 
portanto, é fundamental para refletirmos sobre nossos entendimentos acerca do que é ensinar língua portuguesa e sobre o como estamos fazendo isso.

$\mathrm{Na}$ próxima seção, trago a arquitetura teórica que sustenta as reflexões aqui realizadas, a saber: o conceito de Letramento Crítico (CERVETTI, PARDALES \& DAMICO 2001; MCLAUGHLIN, DEVOOGD, 2004) e os pressupostos teóricos da Linguística sistêmico-funcional e do Sistema de Transitividade (HALLIDAY \& MATTHIESSEN, 2014). Posteriormente, seguem a análise do conto, a discussão das questões a serem abordadas em sala de aula, e por fim, as considerações finais.

\section{ARQUITETURA TEÓRICA}

\section{O letramento crítico}

O termo letramento crítico (doravante, LC) refere-se a uma concepção de trabalho com a linguagem que visa ao desenvolvimento não só das competências comunicativas de ler e escrever, mas também da capacidade de examinar e questionar os significados produzidos discursivamente (MCLAUGHLIN; DEVOOGD, 2004).

Segundo Cervetti, Pardales \& Damico (2001), essa abordagem orienta-se pelos princípios da teoria social crítica e do pensamento de Paulo Freire, os quais preconizam que as injustiças sociais e o sofrimento humano são consequências do controle das ideologias, das instituições e das práticas sociais, por um uma minoria.

Nessa perspectiva, a língua é compreendida como um recurso para criação de sentidos e o discurso, como uma prática social com potencial de reproduzir ou desconstruir as ideologias dominantes, que naturalizam e fortalecem as desigualdades. Sendo assim, todo texto está circunscrito a um determinado contexto sócio-histórico e expressa relações de poder, valores e crenças da cultura em que é produzido.

No LC, textos orais, escritos ou visuais são trabalhados de modo a expor a agenda oculta de grupos dominantes em processo de reflexão sobre os mecanismos que perpetuam estereótipos e preconceitos, silenciam vozes ou apagam identidades. Essa conscientização em contextos pedagógicos é o que Freire (1982) chama de educação libertadora.

Os sentidos criados discursivamente, embora sejam apenas construções sóciohistóricas, moldam as crenças e as ações das pessoas no mundo e, por isso, têm efeitos reais. Ser letrado criticamente significa interpretar os sentidos possíveis de um texto e, principalmente, suas implicações sociais. 
Consequentemente, o LC também possibilita aos educandos e educandas a produção de discursos que constroem novas representações de mundo, desafiando o status quo e transformando sua realidade.

\section{Linguística sistêmico-funcional e o Sistema de Transitividade}

A linguística sistêmico-funcional (HALLIDAY, 1994) busca compreender a linguagem a partir dos seus usos sociais e tem como um de seus principais objetivos investigar como criamos e trocamos sentidos em nossas interações.

Segundo seus pressupostos teóricos, a língua é uma rede de sistemas semióticos que permite a construção de significados por meio de escolhas realizadas pelos falantes/ escritores. Tais escolhas vão depender do contexto, das relações entre os participantes envolvidos e de seus propósitos comunicativos.

A teoria tem, portanto, o potencial de explicitar como as escolhas e o arranjo dos recursos da língua funcionam na criação de sentidos, sem perder de vista os fatores de natureza extralinguística que conduzem a produção e a interpretação de textos orais e escritos. Neste sentido, constitui-se um ferramental de análise com categorias que nos permitem evidenciar no discurso nossas interpretações acerca de um texto.

Halliday (1994) propõe que a linguagem humana desempenha simultaneamente três metafuções: metafunção ideacional, relacionada à representação de experiências; metafunção interpessoal, que reflete e molda a natureza das relações entre os participantes de uma interação, e metafunção textual, responsável pela organização e distribuição das informações no texto.

Cada metafunção é realizada por um sistema da língua, o qual disponibiliza aos seus usuários as estruturas necessárias para criação dos significados que derivam dessas funções. A função ideacional se realiza pelo Sistema de Transitividade, a interpessoal, pelo Sistema de Modo e a textual, pelo Sistema Tema e Rema. Tais sistemas situam-se no nível da lexicogramática (HALLIDAY, 1994) e os sentidos que realizam, no nível da semântica do discurso. Assim, podemos investigar como as funções da linguagem foram estruturadas em um texto pela análise dos elementos de cada sistema, e consequentemente como os usuários da língua utilizam a linguagem para formar sentidos, de acordo com seus objetivos e necessidades.

Neste trabalho, focalizo o Sistema de Transitividade, que realiza a metafunção ideacional, de representação das experiências. Seus recursos lexicogramaticais nos 
possibilitam reconstruir linguisticamente eventos, emoções e pensamentos que vivenciamos no mundo físico e também mundo da consciência. São elementos desse sistema: processos, que representam eventos no mundo externo ou interno dos falantes/ escritores, e se realizam por grupos verbais; participantes, que representam pessoas, seres ou objetos envolvidos em uma experiência, e se realizam por grupos nominais; e circunstâncias, que podem indicar o tempo, o lugar, o modo, entre outros aspectos, e são expressas por grupos adverbiais ou preposicionais.

Os processos subdividem-se ainda em seis categorias: processos materiais, relacionais, mentais, comportamentais, verbais e existenciais, o que também resulta em uma especificação dos tipos participantes.

Assim, os materiais são os processos do fazer como correr, cozinhar, cortar, e têm como participantes um Ator, o agente de uma ação concreta, e uma Meta, participante afetado por tal ação.

Os processos relacionais são usados para caracterizar ou identificar os participantes que, nesse caso, podem ser um Portador e um Atributo, ou um Identificado e um Identificador. São expressos por verbos como ser, estar e ter. Orações relacionais também podem expressar relações de posse e, então, teremos como participantes um Possuidor e um Possuído.

Os processos mentais representam experiências relacionadas à emoção e ao pensamento como amar, apaixonar-se imaginar, perceber. São participantes desses processos um Experienciador e um Fenômeno.

Processos comportamentais situam-se entre os materiais e os mentais. Expressam comportamentos psicológicos como chorar, observar, dançar que resultam, muitas vezes, de estados emocionais, e comportamentos fisiológicos como tossir, dormir, respirar. A maioria das orações comportamentais tem apenas um participante denominado Comportante.

Processos verbais indicam ações que acorrem por meio da fala, como dizer, perguntar, informar. São participantes desses processos o Dizente, quem diz alguma coisa, a Verbiagem, o que é dito, e o Receptor, o destinatário da mensagem. Quando o que é dito vem em forma de uma oração, a mensagem pode ser classificada como Citação, no caso de reprodução integral de uma fala, ou Relato, no caso de reprodução indireta dessa mensagem.

Finalmente, os Processos Existenciais representam algo que existe ou acontece e têm como único participante o Existente. 
A combinação entre processos, participantes e circunstâncias configuram diferentes modos de representar uma experiência. Através da identificação e da análise desses elementos, interpretamos quem, o quê e como está sendo representado.

\section{METODOLOGIA}

A escolha do conto de fadas "A Moça tecelã" se deu com base em dois critérios: i) sua popularidade, já que é um dos mais conhecidos de Marina Colasanti, ii) e o seu potencial para a discussão em sala de aula dos papeis sociais da mulher e do homem, e também das relações amorosas.

Para empreender este estudo, sigo alguns passos baseados em uma metodologia qualitativa de trabalho com o texto:

1. Leitura prévia do conto para levantamento dos elementos ideacionais relacionados às personagens feminina e masculina.

2. Seleção de trechos para a análise.

3. Análise e interpretação da representação da mulher e do homem no conto a partir das categorias do Sistema Ideacional de Transitividade propostas por Halliday (1994).

Os fragmentos do conto foram indicados no corpo do artigo por números entre parênteses, (1), (2), (3), etc; seguindo a ordem em que estes aparecem na análise. Para facilitar a leitura e a compreensão do estudo, os processos, os participantes e as circunstâncias analisadas foram destacados em negrito e o conto encontra-se em anexo.

Primeiro, analisei a representação da personagem feminina e, posteriormente, da personagem masculina. Em seguida, discuto de que modo as escolhas lexicogramaticais da autora constroem essas representações, como estas se distanciam do paradigma tradicional dos contos de fadas e como esse texto pode ser abordado visando ao LC.

\section{ANÁLISE E DISCUSSÃo}

\section{Contextualizando o conto}

“A Moça Tecelã” é o primeiro dos 13 contos de fadas que compõem o livro Doze Reis e a Moça no Labirinto do Vento (1982), de Marina Colasanti. Nele, a personagem principal é uma moça simples que possui um tear mágico. Através desse objeto, ela tem o poder de intervir no mundo ao seu redor e de trazer a existência tudo o 
que deseja. A história se divide em três momentos: antes, durante e depois da chegada de um homem na vida da personagem. Pela análise das categorias ideacionais do conto, interpreto que representações sociais da mulher e do homem são construídas na narrativa.

Porém, tendo em vista a importância do contexto de uso da linguagem na teoria sistêmico-funcional, observar alguns fatores contextuais de produção do conto é fundamental para a análise aqui realizada. Para isso, recorro à Borges e Cánovas (2016), que apresentam considerações importantes sobre os contos de fadas colasantianos e que também dizem respeito ao conto aqui focalizado.

Para os autores, a obra da escritora se inscreve em um paradigma contemporâneo do gênero, o conto de fadas moderno, uma forma "que retoma traços das antigas narrativas populares [os contos tradicionais], mas que, ao mesmo tempo, apresenta princípios estéticos e ideológicos típicos de uma cultura atual.” (BORGES \& CÁNOVAS, 2016, P. 147). Desse modo, o conto moderno de Marina Colasanti seria uma atualização da forma tradicional e refletiria aspectos da cultura em que foi produzido.

A partir de tal concepção, Borges e Cánovas (2016) fazem os seguintes destaques: diferentemente dos contos tradicionais, as narrativas de Colasanti possuem autoria definida e individual e, portanto, a visão de mundo representada no texto passa por sua subjetividade; embora personagens, enredos, temas e ambientação sejam semelhantes aos das histórias canônicas, há em sua produção um tom feminista, marcado pela diferença de postura das personagens femininas (e também masculinas) que "lutam para romper padrões e questionar valores valiosos para a tradição patriarcal" (BORGES\& CÁNOVAS, 2016, P. 147).

É válido destacar também que Colasanti, ao longo de sua carreira como jornalista e escritora, sempre se posicionou explicitamente a favor dos direitos das mulheres e da emancipação feminina, tendo alguns livros escritos sobre o assunto ${ }^{3}$.

Logo, é apoiada em tais aspectos contextuais que elaborei minha interpretação e observá-los em sala de aula é fundamental em uma perspectiva crítica de letramento, pois situa os alunos quanto aos fatores históricos e sociais que também constroem o

\footnotetext{
${ }^{3}$ Cf: A nova mulher (1980); Mulher daqui pra frente (1981); Aqui entre nós (1988).
} 
conto. A seguir, passo a análise das personagens feminina e masculina, a partir dos elementos linguísticos do texto.

\section{Moça tecelã}

A moça tecelã é apresentada aos leitores como uma jovem mulher simples e incomum:

(1) Acordava ainda no escuro, como se ouvisse o sol chegando atrás das beiradas da noite. E logo sentava-se ao tear.

(2) Leve, a chuva vinha cumprimentá-la à janela.

Em (1), combinação das circunstâncias ainda no escuro e logo aos processos acordava e sentava-se ao tear remetem-nos a uma ideia de simplicidade e disciplina. Além disso, a personagem encontra-se em um ambiente doméstico, exercendo uma atividade de tecer tipicamente associada ao universo feminino.

Ainda em (1), ela é a experienciadora do processo mental ouvisse, cujo fenômeno é o sol chegando, e em (2) temos um processo comportamental, cumprimentar, realizado pela participante chuva e que tem como beneficiária a moça tecelã.

A personificação do sol e da chuva, operada pelos processos chegando e cumprimentar, colabora para a construção da protagonista como um ser de atributos extraordinários. Por conta deste recurso, a personagem estabelece com a natureza uma relação humanizada e pessoal que pode ser interpretada como uma sensibilidade especial, pureza de coração, dom, entre outras possibilidades.

A combinação de tais elementos cria no conto uma imagem de mulher ainda muito semelhante ao arquétipo dos contos tradicionais: uma personagem delicada, disciplinada e sensível.

Entretanto, sua característica mais singular é a capacidade de intervir no mundo ao seu redor transformando situações e trazendo a existência novas realidades:

(3) Delicado traço cor de luz, que ela ia passando entre os fios estendidos, enquanto lá fora a claridade da manhã desenhava o horizonte.

(4) Mas se durante muitos dias o vento e o frio brigavam com as folhas e espantavam os pássaros, bastava a moça tecer com seus belos fios dourados, para que o sol voltasse a acalmar a natureza. 
(5) Na hora da fome tecia um lindo peixe, com cuidado de escamas. (...). Se sede vinha, suave era a lã cor de leite que entremeava o tapete. E à noite, depois de lançar seu fio de escuridão, dormia tranquila.

Nos trechos acima, os processos materiais destacados têm como agente a moça tecelã e são todos ligados à sua atividade de tecer. Em (4), pode-se observá-la atuando sobre as forças da natureza a fim de transformar uma situação de desequilíbrio. Já os fragmentos (3) e (5) sugerem que a própria passagem do tempo e os acontecimentos da vida dependiam do seu trabalho. Isso se evidencia pelo paralelismo que há no texto entre a ação de tecer da personagem e as transformações ocorridas no mundo exterior. Ainda em (5), pode-se notar também que ela tem o poder de prover para si mesma tudo o que necessita.

Logo, na primeira parte da história, é possível compreender que a moça tecelã não é como as típicas personagens femininas dos contos de fadas, uma vez que ela mesma tem o poder de agir em seu universo e que figura como uma jovem independente. No decorrer da narrativa, tais características ficam ainda mais notórias.

O elemento complicador da trama é o marido que, ao descobrir o poder do tear, obriga a moça a tecer todos os seus caprichos e a aprisiona em uma masmorra. Entretanto, o aparecimento do homem na história ocorre pelo desejo e pela ação da própria moça tecelã, o que, em minha leitura, maximiza o seu poder e a sua autonomia:

(6) Mas tecendo e tecendo, ela própria trouxe o tempo em que se sentiu sozinha, e pela primeira vez pensou como seria bom ter um marido ao seu lado. (...) E aos poucos seu desejo foi aparecendo, chapéu emplumado, rosto barbado, corpo aprumado, sapato engraxado.

O fragmento (6) indica que não foi outra pessoa ou uma força externa quem mudou os rumos da narrativa, como geralmente ocorre nos contos de fada. Além disso, a circunstância Mas tecendo e tecendo indica de que modo todos os esses eventos se realizam, reforçando a agentividade da protagonista, ou seja, a sua autoria em relação aos eventos que lhe sucedem.

Ainda que trabalhando sob as ordens do marido, a jovem não perde o controle sobre o tear e, novamente, tecendo ela determina outra direção para a história, dando início ao terceiro momento do conto. Nesta última parte, ela desfaz tudo o que havia tecido a mando do marido, e todas as exigências da personagem masculina tornam-se metas do processo material destecer, como podemos observar no fragmento (7): 
(7) Desteceu os cavalos, as carruagens, as estrebarias, os jardins. Depois desteceu os criados e o palácio e todas as maravilhas que continha.

O próprio marido é desfeito pela moça no tear e partes do corpo do homem se tornam metas dos processos desaparecendo e sumindo:

(8) e ele viu seus pés desaparecendo, sumindo as pernas.

De volta à sua casa, a mulher é representada pelo processo comportamental sorriu, associado ao grupo preposicional para o jardim, que indica orientação:

(9) E novamente se viu na sua casa pequena e sorriu para o jardim além da janela.

Essa interação com o jardim sugere que a personagem retornou ao estado inicial da narrativa, o que fica mais evidente com a repetição de fragmentos iniciais do conto encerrando o texto:

(10) Então, como se ouvisse a chegada do sol, a moça escolheu uma linha clara. E foi passando-a devagar entre os fios, delicado traço de luz, que a manhã repetiu na linha do horizonte.

Embora seja caracterizada como uma mulher sensível e delicada, a personagem feminina é, ao mesmo tempo, forte e poderosa uma vez que controla o objeto mágico da narrativa e pode interferir e modificar o mundo ao seu redor através do ato de tecer. Ao contrário das protagonistas de contos tradicionais, não fica a mercê da atuação de outros personagens, como uma fada madrinha ou um príncipe, para solucionar o seu problema. Da mesma forma é a própria personagem e não um antagonista que já atua na história quem provoca a situação complicadora da narrativa, a chegada do marido.

\section{Marido}

Em "A moça tecelã", a personagem masculina é um marido que aparece na história alterando o estado inicial do conto, de equilíbrio e harmonia. A escolha do substantivo "marido", no lugar de "príncipe", já sugere uma representação incomum dessa personagem. 
Em contos de fadas tradicionais, a figura do príncipe agrega diversas ações positivas de coragem e bondade, que, frequentemente, resultam no resgate da protagonista de alguma situação de perigo ou de algum encantamento.

Nesta história, a chegada da personagem masculina, que é um marido, é o próprio fato complicador da narrativa e vai desencadear as situações de sofrimento vivenciadas pela moça tecelã.

Como é possível observar no fragmento a seguir, a entrada da personagem na trama se dá de modo violento:

(11)O moço meteu a mão na maçaneta, tirou o chapéu de pluma, e foi entrando na sua vida.

Os processos materiais meteu e foi entrando remetem à ideia de brutalidade e invasão e funcionam como um prenúncio dos acontecimentos posteriores. Ao descobrir o poder do tear, ele exige que a moça teça todos os seus caprichos e, então, aparecem no texto vários processos verbais como ordenar, advertir, e exigir que compõem o seu autoritarismo:

(12)Exigiu que escolhesse as mais belas lãs cor de tijolo, fios verdes para os batentes, e pressa para a casa acontecer.

(13)Para que ter casa, se podemos ter palácio? - perguntou. Sem querer resposta, imediatamente ordenou que fosse de pedra com arremates em prata.

(14)E antes de trancar a porta à chave, advertiu: - Faltam as estrebarias

Além de violento e autoritário, o marido é caracterizado como ambicioso, apegado aos bens materiais e ao luxo. Nesse sentido, ele também se opõe à personagem feminina, ligada à simplicidade e à natureza. Já as circunstâncias sem querer resposta, imediatamente e antes de trancar a porta à chave indicam um comportamento impaciente e tirano, bem como a situação de dominação vivenciada pela protagonista. Outros fragmentos também apontam para tal condição:

(15)Sem descanso tecia a mulher os caprichos do marido, enchendo o palácio de luxos, os cofres de moedas, as salas de criados.

(16)Tecia e entristecia, enquanto sem parar batiam os pentes acompanhando o ritmo da lançadeira.

Como podemos perceber, a partir dessa análise, a figura masculina é representada de modo negativo, sendo caracterizada como violenta, gananciosa, 
possessiva e dominadora. Apesar de agir conforme o sistema de valores patriarcal, sua ações no conto nos levam a refletir sobre o comportamento dos homens em suas relações cotidianas e indicam que a representação convencional escamoteia realidades sociais de assimetria e opressão entre homens e mulheres.

\section{Abordando o conto em sala de aula sob a perspectiva crítica}

"A moça tecelã" oportuniza a discussão de vários aspectos da vida social, porém, antes de abordá-los em sala de aula, é importante situar o aluno quanto ao gênero a que pertence o texto e quanto a outros elementos do seu contexto de produção como o período em que foi escrito e quem é Marina Colasanti. Assim, é fundamental abordar as características do conto de fadas moderno e aspectos da vida da autora que possam ser relevantes para a compreensão dos sentidos negociados durante a leitura.

Em meu entendimento, a questão central da história é o relacionamento abusivo vivenciado pela personagem feminina. Vale observar como era a vida da moça tecelã antes e depois da chegada do marido, de que modo ele a tratou ao longo da trama, o seu comportamento violento e autoritário e por que isso não é aceitável.

Outro aspecto interessante é o desfecho da narrativa, pois representa a superação da personagem feminina de uma relação de desrespeito e violência. Quanto a isso, destaco as características da protagonista, o fato de ela ser forte, independente, de ter poder e de agir para transformar as situações à sua volta.

As representações contra-hegemônicas das figuras feminina e masculina também nos levam a questionar valores socialmente construídos e disseminados em nossa cultura sobre o relacionamento entre homens e mulheres. O enlace amoroso não aparece na história como o fim desejado, o que desconstrói a noção do casamento como fonte de realização pessoal feminina. Ao contrário, no conto, a realização da mulher se dá pela sua atividade no tear, e já ocorria antes do aparecimento do marido na história.

Promover esses questionamentos no contexto pedagógico possibilita o diálogo e o confronto entre os valores que subjazem ao texto e a visão de mundo dos participantes da leitura (estudantes e professores).

O letramento crítico não exclui o ensino de estruturas gramaticais e o desenvolvimento de habilidades comunicativas. Porém, neste artigo, desejei dar maior destaque aos processos de reflexão, pois acredito que incorporar práticas questionadoras ao ensino de língua portuguesa enriquece as atividades em sala de aula e promove um 
trabalho conectado a questões da cultura em que estamos inseridos e que contempla a formação do aluno como um todo.

\section{CONSIDERAÇÕES FINAIS}

A partir dessa análise, podemos observar que o conto desconstrói o discurso patriarcal que constantemente representa as figuras femininas de modo frágil, dependente e passivo, contribuindo para que as mulheres sejam vistas como inferiores por outros homens e também por nós mesmas.

As atitudes da personagem rompem com uma postura de passividade em relação às suas vivências e, mais especificamente, de submissão em um relacionamento abusivo. O seu comportamento reflete um sistema de valores próprio de nossa época e ao mesmo tempo contribui para fortalecê-lo.

Já a figura masculina ao invés de ser um príncipe que salva a protagonista, aparece como um marido ambicioso, violento e tirano, que será o elemento complicador da narrativa.

Em um pequeno conto, Marina Colasanti descontrói visões cristalizadas da figura feminina, da figura masculina e também do casamento, promovendo reflexões acerca do papel da mulher na sociedade e na família e também em torno do que nos é apresentado como desejável ou como um alvo a ser perseguido pelas mulheres, o casamento.

Por fim, discorri brevemente sobre a abordagem de tais questões no contexto pedagógico em uma perspectiva crítica de letramento. Além de colaborar para a formação de uma postura reflexiva, tal discussão tem o potencial de promover sistemas de crenças que não resultem em sofrimento, marginalização ou preconceito contra mulheres e sim em visões de mundo em que homens e mulheres sejam tratados com igualdade, orientadas por uma perspectiva ética e compromissada com a transformação social.

\section{REFERÊNCIAS}

BORGES, K.J.S; CÁNOVAS, S.Y.M.L. O conto de fadas moderno: a atualização do gênero na obra infantojuvenil de Marina Colasanti. In FronteiraZ - Revista do 
Programa de Estudos Pós-Graduados em Literatura e Crítica Literária da PUCSP $\quad \mathrm{n}^{\mathrm{o}} \quad 17, \quad 2016.2$ Disponível http://revistas.pucsp.br/index.php/fronteiraz/article/view/28872/21330.

CERVETTI, G.; PARDALES, M. J.; DAMICO, J. S. A tale of differences: comparing the traditions, perspectives and educational goals of critical reading and critical literacy. Reading Online, v. 4, n. 9, 2001.

COELHO, N. N. Literatura infantil: teoria - análise - didática. São Paulo: Moderna, 2000.

2008

O conto de fadas: símbolos, mitos, arquétipos. São Paulo: Paulinas,

COLASANTI, M. A moça tecelã In: Doze reis e a moça no labirinto do vento. $6^{\text {a }}$ edição. Rio de Janeiro: Nórdica, 1982.

FREIRE, P. Pedagogia do oprimido. $11^{\text {a }}$ ed. Rio de Janeiro: Paz e Terra, 1982.

HALLIDAY, M. A. K. An Introduction to Functional Grammar. London: Arnold, 1994.

HAllidAY, M. A. K.; HASAN, R. Language, Context, e Text. Aspects of Language in a Social-semiotic Perspective. Oxford: Oxford University Press, 1989.

HALliDAY, M. A. K., MATHIESSEN, C. An Introduction to Functional Grammar. $3^{\text {a }}$ edição. London: Arnold, 2014.

MCLAUGHLIN, M.; DEVOOGD, G. L. Critical Literacy as Comprehension: Expanding Reader Response, 2004. Journal of Adolescent \& Adult Literacy, Vol. 48, No. 1 (Sep., 2004), pp. 52-62.

\section{A AUTORA}

Julia Rodrigues Chagas Cabral é graduada em Letras pela Universidade Federal do Rio de Janeiro -UFRJ e atualmente cursa o metrado em Estudos da Linguagem na Pontifícia Universidade Católica do Rio de Janeiro.

E-mail: juliarchagascabral@gmail.com 


\begin{abstract}
ANEXO
A Moça Tecelã

Acordava ainda no escuro, como se ouvisse o sol chegando atrás das beiradas da noite. E logo sentava-se ao tear.

Linha clara, para começar o dia. Delicado traço cor de luz, que ela ia passando entre os fios estendidos, enquanto lá fora a claridade da manhã desenhava o horizonte.

Depois lãs mais vivas, quentes lãs iam tecendo hora a hora, em longo tapete que nunca acabava.

Se era forte demais o sol, e no jardim pendiam as pétalas, a moça colocava na lançadeira grossos fios cinzentos de algodão mais felpudo. Em breve, na penumbra trazida pelas nuvens, escolhia um fio de prata, que em pontos longos rebordava sobre o tecido. Leve, a chuva vinha cumprimentá-la à janela.

Mas se durante muitos dias o vento e o frio brigavam com as folhas e espantavam os pássaros, bastava a moça tecer com seus belos fios dourados, para que o sol voltasse a acalmar a natureza.

Assim, jogando a lançadeira de um lado para o outro e batendo os grandes pentes do tear para frente e para trás, a moça passava os seus dias.

Nada lhe faltava. Na hora da fome tecia um lindo peixe, com cuidado de escamas. E eis que o peixe estava na mesa, pronto para ser comido. Se sede vinha, suave era a lã cor de leite que entremeava o tapete. E à noite, depois de lançar seu fio de escuridão, dormia tranquila.

Tecer era tudo o que fazia. Tecer era tudo o que queria fazer.

Mas tecendo e tecendo, ela própria trouxe o tempo em que se sentiu sozinha, e pela primeira vez pensou como seria bom ter um marido ao seu lado.

Não esperou o dia seguinte. Com capricho de quem tenta uma coisa nunca conhecida, começou a entremear no tapete as lãs e as cores que lhe dariam companhia. E aos poucos seu desejo foi aparecendo, chapéu emplumado, rosto barbado, corpo aprumado, sapato engraxado. Estava justamente acabando de entremear o último fio da ponta dos sapatos, quando bateram à porta.

Nem precisou abrir. O moço meteu a mão na maçaneta, tirou o chapéu de pluma, e foi entrando na sua vida.
\end{abstract}


Aquela noite, deitada contra o ombro dele, a moça pensou nos lindos filhos que teceria para aumentar ainda mais a sua felicidade.

E feliz foi, durante algum tempo. Mas se o homem tinha pensado em filhos, logo os esqueceu. Porque, descoberto o poder do tear, em nada mais pensou a não ser nas coisas todas que ele poderia lhe dar.

- Uma casa melhor é necessária, -- disse para a mulher. E parecia justo, agora que eram dois. Exigiu que escolhesse as mais belas lãs cor de tijolo, fios verdes para os batentes, e pressa para a casa acontecer.

Mas pronta a casa, já não lhe pareceu suficiente. - Para que ter casa, se podemos ter palácio? - perguntou. Sem querer resposta, imediatamente ordenou que fosse de pedra com arremates em prata.

Dias e dias, semanas e meses trabalhou a moça tecendo tetos e portas, e pátios e escadas, e salas e poços. A neve caía lá fora, e ela não tinha tempo para chamar o sol. A noite chegava, e ela não tinha tempo para arrematar o dia. Tecia e entristecia, enquanto sem parar batiam os pentes acompanhando o ritmo da lançadeira.

Afinal o palácio ficou pronto. E entre tantos cômodos, o marido escolheu para ela e seu tear o mais alto quarto da mais alta torre.

- É para que ninguém saiba do tapete, -- disse. E antes de trancar a porta à chave, advertiu: -- Faltam as estrebarias. E não se esqueça dos cavalos!

Sem descanso tecia a mulher os caprichos do marido, enchendo o palácio de luxos, os cofres de moedas, as salas de criados. Tecer era tudo o que fazia. Tecer era tudo o que queria fazer.

E tecendo, ela própria trouxe o tempo em que sua tristeza lhe pareceu maior que o palácio com todos os seus tesouros. E pela primeira vez pensou como seria bom estar sozinha de novo.

Só esperou anoitecer. Levantou-se enquanto o marido dormia sonhando com novas exigências. E descalça, para não fazer barulho, subiu a longa escada da torre, sentou-se ao tear.

Desta vez não precisou escolher linha nenhuma. Segurou a lançadeira ao contrário, e, jogando-a veloz de um lado para o outro, começou a desfazer o seu tecido. Desteceu os cavalos, as carruagens, as estrebarias, os jardins. Depois desteceu os criados e o palácio e todas as maravilhas que continha. E novamente se viu na sua casa pequena e sorriu para o jardim além da janela. 
A noite acabava quando o marido, estranhando a cama dura, acordou e, espantado, olhou em volta. Não teve tempo de se levantar. Ela já desfazia o desenho escuro dos sapatos, e ele viu seus pés desaparecendo, sumindo as pernas. Rápido, o nada subiu-lhe pelo corpo, tomou o peito aprumado, o emplumado chapéu.

Então, como se ouvisse a chegada do sol, a moça escolheu uma linha clara. E foi passando-a devagar entre os fios, delicado traço de luz, que a manhã repetiu na linha do horizonte.

Colasanti, Marina. Doze reis e a moça no labirinto do vento. $6^{\text {a }}$ edição. Rio de Janeiro: Nórdica, 1982. 